\title{
Enhancing the natural killer cell activity and anti-influenza effect of heat-treated Lactobacillus plantarum nF1-fortified yogurt in mice
}

\author{
Da Hyun Kim, ${ }^{* 1}$ Woo-Chang Chung, $\dagger^{1}$ Su-hyun Chun, ${ }^{*}$ Ji Ho Han, $\dagger$ Moon Jung Song, $\dagger^{2}$ \\ and Kwang-Won Lee*2 \\ *Department of Biotechnology, College of Life Sciences and Biotechnology, Korea University, Seoul 02841, Republic of Korea \\ †Virus-Host Interactions Laboratory, Department of Biosystems and Biotechnology, College of Life Sciences and Biotechnology, Korea University, \\ Seoul 02841, Republic of Korea
}

\section{ABSTRACT}

Influenza A virus (IAV) infection is a global public health concern. It causes respiratory diseases ranging from mild illness to fatal disease. Natural killer (NK) cells are an innate immune component that kill infected cells and secrete cytokines to modulate the adaptive immune system; they constitute the first-line defense and play important roles in controlling IAV infection. This study evaluated the effect of daily administration of heat-treated Lactobacillus plantarum $\mathrm{nF} 1$-fortified yogurt on immunity and protection against IAV infection. Mice administered with heat-treated L. plantarum nF1-fortified yogurt showed elevated NK cell-related cytokine expression levels. Daily administration of the L. plantarum $\mathrm{nF} 1$-fortified yogurt before IAV infection also enhanced splenic NK activity, lung inflammatory cytokine responses, and survival rate. Thus, daily administration of $\mathrm{nF} 1$-fortified yogurt enhances host immunity and helps prevent IAV infection.

Key words: yogurt, natural killer cell activity, antiinfluenza, heat-treated Lactobacillus plantarum $\mathrm{nF} 1$

\section{INTRODUCTION}

Influenza A virus (IAV) infection is a global public health concern (Palese, 2004). Influenza A virus causes respiratory diseases ranging from mild illness to fatal disease; it is associated with high morbidity and mortality, depending on the viral strain and host immunocompetence (Taubenberger and Morens, 2008, 2010). The IAV is a member of the Orthomyxoviridae family, which has a single-stranded, negative sense RNA genome. The innate immune system acts as the first-line

Received May 31, 2018.

Accepted August 23, 2018.

${ }^{1}$ These authors contributed equally to this study.

${ }^{2}$ Corresponding authors: moonsong@korea.ac.kr and kwangwon@ korea.ac.kr of defense against IAV infection (Kreijtz et al., 2011). Natural killer (NK) cells play important roles in defense against IAV infection by killing IAV-infected cells and producing cytokines as part of the innate immune response. This can limit the IAV infection and develop an adaptive immune response (Schultz-Cherry, 2015). Therefore, modulation of NK cell activity may boost immunity against IAV infection.

Natural killer cells are large granular lymphocytes that participate in innate immune responses. Key responses of NK cells include killing stressed, cancerous, or infected cells and producing cytokines (Vivier et al., 2008). Natural killer cells are stimulated by immunerelated, cell-produced cytokines, such as interleukins and Type I IFN, which are among the earliest responses of the innate immune system, as well as other activating molecules on the surface of stressed cells (Vivier et al., 2008; Sun and Lanier, 2011; Geiger and Sun, 2016). Cytokine-activated NK cells are more cytotoxic than resting NK cells, and the cytotoxicity is downregulated by recognizing major histocompatibility complex class I molecules and inhibitory non- major histocompatibility complex class I molecules of target cells. Key responses of NK cells include the production of cytolytic granules, such as perforin and granzymes, which lyse stressed cells, and the secretion of cytokines, such as IFN- $\gamma$ and tumor necrosis factor- $\alpha$, which regulate other immune cell responses (Lanier, 2008; Orr and Lanier, 2010).

Yogurt is milk that has been fermented by either Streptococcus thermophilus or Lactobacillus delbrueckii, with or without additional cultures (Codex Alimentarius, 2010). It contains probiotics and bioactive compounds produced by lactic acid bacteria (LAB) during fermentation. Lactic acid bacteria-fermented milk products affect immune responses; for example, by enhancing NK cell activity (Nishimura et al., 2015; Makino et al., 2016; Shida et al., 2017). Consuming $\mathrm{LAB}$ or LAB-fermented products may also reduce infection risk and enhance anti-influenza activity (Goto et al., 2013; Kawahara et al., 2015; Meng et al., 2016). 
Lactobacillus plantarum $\mathrm{nF} 1$ ( $\mathbf{n F 1} \mathbf{1})$ is a LAB isolated from kimchi, a traditional Korean dish made using fermented cabbage that has been shown to exert beneficial effects on the immune system (Lee et al., 2016a; Choi et al., 2018). Consumption of heat-treated $n F 1$-fortified yogurt has been shown to improve immune functions, including NK cell activity, in elderly individuals (Lee et al., 2017). Some L. plantarum strains have also been reported to exert protective effects against influenza viruses (Maeda et al., 2009; Arimori et al., 2012; Kikuchi et al., 2014).

Our study aimed to test whether administering heat-treated $\mathrm{nF} 1$-fortified yogurt enhances immunomodulatory properties, including NK cell activity. We also evaluated the effects of administering $\mathrm{nF} 1$-fortified yogurt against preventing influenza virus infection in mice infected with a lethal dose of IAV.

\section{MATERIALS AND METHODS}

\section{Cells and Materials}

Madin-Darby canine kidney (MDCK) cells (Korean Cell Line Bank, Seoul, Korea) were cultured in complete DMEM medium (PAN Biotech, Aidenbach, Germany) containing 10\% fetal bovine serum (FBS; PAN Biotech) supplemented with $100 \mathrm{U} / \mathrm{ml}$ of penicillin and $100 \mathrm{~g} / \mathrm{mL}$ of streptomycin (Gibco, Thermo Fisher Scientific, Waltham, MA). A mouse lymphoma cell line, YAC-1 (Korea Cell Line Bank), was cultured in complete RPMI-1640 medium (Sigma-Aldrich, St. Louis, MO) containing 10\% FBS (Hyclone, GE Healthcare Life Sciences, Pittsburgh, PA) supplemented with $2 \mathrm{~m} M$ L-glutamine (Sigma-Aldrich), $25 \mathrm{~m} M$ HEPES (Sigma-Aldrich), $100 \mathrm{U} / \mathrm{mL}$ of streptomycin, and 100 $\mathrm{U} / \mathrm{mL}$ of penicillin (Hyclone). The cells were maintained at $37^{\circ} \mathrm{C}$ in a humidified incubator containing $5 \% \mathrm{CO}_{2}$. Avertin (2,2,2-tribromoethanol and tert-amyl alcohol) was purchased from Sigma-Aldrich.

\section{Preparation of Yogurt Samples}

Powdered yogurt (PY), whole milk powder, and heattreated $\mathrm{nF} 1$ were provided by Purmil Co. Ltd. (Seoul, Korea) and stored at $4^{\circ} \mathrm{C}$. Yogurt was fermented with a starter culture containing Lactbacillus acidophilus, $L$. delbrueckii ssp. bulgaricus, S. thermophilus, Bifidobacterium, Lactobacillus paracasei (L. casei 431), and Bifidobacterium lactis (BB-12) obtained from Chr. Hansen A/S (Hørsholm, Denmark). Heat-treated L. plantarum $\mathrm{nF} 1$ powder was purchased from Biogenics Korea Co. Ltd. (Seoul, Korea) and added after fermentation. We prepared the first treatment (PY1) by reconstituting
Table 1. Composition of milk and yogurt samples ${ }^{1}$

\begin{tabular}{lccrr}
\hline Solid content $(\mathrm{mg} / \mathrm{d})$ & CON & Milk & PY1 & PY2 \\
\hline Milk & - & 29.60 & 29.60 & 29.60 \\
Skim milk & - & - & 5.88 & 5.88 \\
Probiotic strain mixture $^{2}$ & - & - & 0.02 & 0.02 \\
nF1 $^{3}$ & - & - & 0.50 & 2.50 \\
Total $^{3}$ & - & 29.60 & 36.00 & 38.00 \\
\hline
\end{tabular}

${ }^{1} \mathrm{CON}=\mathrm{PBS}$ only; Milk $=$ nonfermented milk only; PY1 $=0.5 \mathrm{mg}$ of $\mathrm{nF} 1$-containing yogurt; PY2 $=2.5 \mathrm{mg}$ of $\mathrm{nF} 1$-containing yogurt.

${ }^{2}$ Lactobacillus acidophilus, Lactobacillus delbrueckii ssp. bulgaricus, Streptococcus thermophilus, Bifidobacterium, Lactobacillus paracasei, and Bifidobacterium lactis.

${ }^{3} \mathrm{nF} 1$ = heat-treated Lactobacillus plantarum $\mathrm{nF} 1$. Only powdered $\mathrm{nF} 1$ was added after fermentation.

powdered $\mathrm{nF} 1$-fortified yogurt in PBS. The second treatment (PY2) was made with 5 times more $\mathrm{nF} 1(2.5$ $\mathrm{mg} / \mathrm{d})$ compared with PY1 $(0.5 \mathrm{mg} / \mathrm{d})$. Milk treatment was the reconstituted form of whole milk powder in PBS, and PBS solution was used as the control group $(\mathbf{C O N})$. Table 1 presents a complete list of ingredients used for the preparation of all samples.

\section{IAV Preparation}

Mouse-adapted A/Puerto Rico/8/34 H1N1 (PR8) strain of IAV was obtained from the International Vaccine Institute, Seoul, Republic of Korea. The virus titer was calculated by median tissue culture infection doses $\left(\mathbf{T C I D}_{50}\right.$ ) assay using MDCK cells (Szretter et al., 2013). Briefly, $100 \mu \mathrm{L}$ of diluted virus stock was inoculated into MDCK monolayers in a 96-well cell culture plate with a 2-h adsorption time. The cells were washed with serum-free media and incubated with IAV growth media containing $2 \mu \mathrm{g} / \mathrm{mL}$ of TPCK-trypsin (SigmaAldrich). The degree of cytopathic effect of each well was evaluated $3 \mathrm{~d}$ postinfection (dpi).

\section{Animal Experiments}

Animal Care and Ethics Statements. Eight-weekold male BALB/c mice were purchased from Samtako (Osan, Korea). The mice were acclimated for $7 \mathrm{~d}$ before oral administration. The animal care environment was maintained at 20 to $24^{\circ} \mathrm{C}$ with a $12 \mathrm{~h}$ light/dark cycle. Water and standard chow were provided ad libitum. All animal experiments were reviewed and approved by the Institutional Animal Care and Use Committee (No. KUIACUC-2016-61) of Korea University, Seoul, Korea.

Oral Administration and Infection Model. To evaluate the immune-enhancing effect of $\mathrm{nF} 1$-fortified yogurt, mice were orally administered $200 \mu \mathrm{L}$ of samples $(\mathrm{n}=24)$ each day for $28 \mathrm{~d}$. The mice were then 
euthanized, and the thymus and spleen were collected for further analysis. Spleen, thymus, and body weights were measured, and organ index was calculated using the formula: organ index $(\%)=$ organ weight $(\mathrm{g}) / \mathrm{BW}$ $(\mathrm{g}) \times 100$.

To evaluate the antiviral effect of $\mathrm{nF} 1$-fortified yogurt, 2 sets of experiments were performed. Mice were orally administered with $200 \mu \mathrm{L}$ of treatment samples each day for $21 \mathrm{~d}$ in a conventional animal care unit. They were then transferred to a biosafety level 2 unit, acclimated for $3 \mathrm{~d}$, and intranasally infected with the PR8 virus under anesthetic conditions using avertin (Sigma-Aldrich; $250 \mu \mathrm{g} / \mathrm{kg}$ ). To examine the NK activity and inflammation response in infected mice, mice ( $\mathrm{n}=6$ per group) were infected with a sublethal dose $\left[0.5 \times\right.$ median lethal doses $\left.\left(\mathbf{L D}_{50}\right) ; 0.5 \times 10^{2.17} \mathrm{TCID}_{50}\right]$ of PR8. At $5 \mathrm{dpi}$, the mice organs were collected for further analysis. To evaluate survival, the mice were infected with a $2 \times \mathrm{LD}_{50}\left(2 \times 10^{2.17}\right.$ TCID $\left._{50}\right)$ dose of PR8 per mouse ( $\mathrm{n}=20$ per group) following the same procedure described above. Mortality was monitored until 21 dpi. Mice that lost $>25 \%$ of their original BW were euthanized following the protocol (No. KUIACUC-2016-61).

Quantitative Reverse Transcription PCR. To test cytokine expression levels in the spleens of each sample group, total RNA was isolated from the spleen using RNAiso plus reagent (TaKaRa, Shiga, Japan) and cDNA was synthesized using the LeGene Premium Express 1st strand cDNA synthesis system (LeGene, San Diego, CA). Gene expression levels were measured by quantitative reverse transcription PCR amplification using the iQ5 real-time PCR detection system (Bio-Rad, Hercules, CA) with HiPi SYBR green $2 \times$ master mix (Elpis, Daejon, Korea). Data were analyzed following the $2^{-\Delta \Delta \mathrm{Ct}}$ method (Livak and Schmittgen, 2001) and normalized using $R n 18 s$ as the housekeeping gene.

To test cytokine levels in the lungs of infected mice, total RNA was extracted using Tri reagent (MRC, Cincinnati, $\mathrm{OH}$ ) and purified using the Qiagen RNeasy mini kit (Qiagen, Hilden, Germany). The cDNA was synthesized using the RevertAid First strand cDNA synthesis kit (Thermo Fisher Scientific) with oligo-dTs. Transcripts were quantified using the following primers for target genes Il1b, Il6, and Actb. Data were analyzed using the $2^{-\Delta \Delta \mathrm{Ct}}$ method (Livak and Schmittgen, 2001) and normalized using Actb as the housekeeping gene. Real-time PCR was performed and analyzed on a Rotor-Gene Q (Qiagen). Table 2 presents the sequences of the primer used for quantitative reverse transcription PCR.

Splenic NK Cell Activity. The NK cell activity of splenocytes was measured as the cytotoxicity of NK cells against target cells using lactate dehydrogenase (LDH) assay (Yu et al., 2016). To obtain splenocytes, the collected spleens were homogenized in Hanks' balanced salt solution (Sigma-Aldrich) and passed through a cell strainer (pore size, $70 \mu \mathrm{m}$; SPL, Gyenonggi-do, Korea) immediately after sacrifice. Red blood cells were obtained using ACK buffer $\left(150 \mathrm{mM} \mathrm{NH} \mathrm{NH}_{4} \mathrm{Cl}, 10 \mathrm{mM}\right.$ $\mathrm{KHCO}_{3}$, and $0.1 \mathrm{mM} \mathrm{Na} 2 \mathrm{EDTA}$ ) and washed twice with Hanks' balanced salt solution. Splenocytes were re-suspended in RPMI 1640 (without phenol red; Sigma-Aldrich) with $10 \%$ FBS, $100 \mathrm{U} / \mathrm{mL}$ of streptomycin, and $100 \mathrm{U} / \mathrm{mL}$ of penicillin (Hyclone). To measure NK cell cytotoxicity, YAC-1 was used as the target cell, whereas splenocytes were used as effector cells. The NK cell cytotoxicity against YAC-1 cells was measured by LDH leakage after $4 \mathrm{~h}$ cocultured supernatant (effector: target $=50: 1)$ using the LDH assay kit, and absorbance was measured at $490 \mathrm{~nm}$ using a commercial colorimetric LDH kit (DoGen, Seoul, Korea) and microplate reader (Hidex, Turku, Finland). The percentages of NK cell activity were calculated using the formula: NK cell cytotoxicity $(\%)=\left(A_{c}-A_{t}\right) /\left(A_{l}-A_{t}\right)$, where $A_{c}$ is the absorbance of cocultured media, $A_{t}$ is the absorbance of the target cell cultured media, and $A_{l}$ is the absorbance of the target cells; cell lysis buffer was provided in the LDH assay kit.

\section{Statistics}

All results are expressed as mean \pm standard deviation. Significant differences against the control or the virus group were analyzed using the 2-tailed Student's $t$-test or unpaired $t$-test. Sample size for each experiment has been indicated in footnotes.

Table 2. Primers used for quantitative PCR

\begin{tabular}{lll}
\hline Gene & Direction & Sequence \\
\hline Rn18s & Forward & GTAACCCGTTGAACCCCATT \\
& Reverse & CCATCCAATCGGTAGTAGCG \\
Ifna & Forward & TGTCTGATGCAGCAGGTGG \\
& Reverse & AAGACAGGGCTCTCCAGAC \\
Il2 & Forward & CCTGAGCAGGATGGAGAATACA \\
& Reverse & TCCAGAACATGCCGCAGAG \\
Il12 & Forward & GGAAGCACGGCAGCAGAATA \\
& Reverse & AACTTGAGGGAGAAGTAGGAATGG \\
Klrb1 & Forward & TCATCCTCCTTGTCCTGACC \\
& Reverse & TTGAATGAGCAGCAAAGTGG \\
Cd69 & Forward & TGGTCCTCATCACGTCCTTAATAA \\
& Reverse & TCCAACTTCTCGTACAAGCCTG \\
Il1b & Forward & CAACCAACAAGTGATATTCTCCATG \\
& Reverse & GATCCACACTCTCCAGCTGCA \\
Il6 & Forward & TCCATCCAGTTGCCTTCTTG \\
& Reverse & GGTCTGTTGGGAGTGGTATC \\
Actb & Forward & GTATCCTGACCCTGAAGTACC \\
& Reverse & TGAAGGTCTCAAACATGATCT \\
\hline
\end{tabular}




\section{RESULTS}

To evaluate the effects of administering heat-treated $\mathrm{nF}$ 1-fortified yogurt on NK cell activation or on IAV infection, mice were consecutively administered with the following samples daily (Table 1): PY1 and PY2 samples were prepared by reconstituting powdered $\mathrm{nF}$ 1-fortified yogurt in PBS with increasing amounts of $\mathrm{nF} 1(0.5 \mathrm{mg} / \mathrm{d}$ for PY1 and $2.5 \mathrm{mg} / \mathrm{d}$ for PY2). The PBS and milk-administered groups were used as controls. As mentioned in Table 1, because heat-treated $L$. plantarum $\mathrm{nF} 1$ was added only after fermentation with starter culture strains was terminated, the fermentation process was not influenced by the heat-treated $\mathrm{nF} 1$.

\section{Effects of Administering nF1-Fortified Yogurt on Normal Mice Model}

To evaluate any immune-enhancing effects of $\mathrm{nF} 1-$ fortified yogurt administration, mice were orally administered yogurt each day. After $28 \mathrm{~d}$, we compared weight changes of the spleen and thymus. Organ index (percentage of organ weight over whole BW) was used to eliminate the effect of organ weight changes that were related to whole BW changes. Compared with $\mathrm{CON}$, no significant difference was observed in BW at $28 \mathrm{~d}$ in groups with additional calorie intake (data not shown). We observed no significant difference in spleen indices (Figure 1A); however, the thymus indices were significantly higher in the milk and PY2 groups than in the CON group $(P=0.029$ and $P<0.001$, respectively). We found no significant difference between the thymus index of PY1 and CON $(P=0.115$; Figure 1B).

To examine the effect of $\mathrm{nF} 1$-fortified yogurt administration on cytokine expression, we measured cytokine mRNA transcript levels in the spleen (Figure 2). The PY1 group showed higher levels of Il2 and Il12 expression than did the CON group $(P=0.036$ and $P=$ 0.048 , respectively). The PY2 group showed significantly higher Ifna, Il2, and Il12 transcript levels than did the CON group $(P=0.014, P<0.001$, and $P=$ 0.005 , respectively). The transcript levels of the Klrb1, a membrane antigen of NK cells, and Cd69, the differentiation antigen Cd69 of activated NK or T cells also increased but less significantly different than cytokine expressions $(P=0.089$ and $P=0.075)$. These results suggest that $\mathrm{nF} 1$-fortified yogurt may increase cytokine transcript levels and thymus weight.

\section{Effects of nF1-Fortified Yogurts on Splenic NK Activity Against IAV Infection}

To evaluate the effect of nF1-fortified yogurt administration before IAV infection on NK cell activity, we infected BALB/c mice with $0.5 \times \mathrm{LD}_{50}$ dose of PR8 following daily yogurt administration and examined splenic NK cell activity at 5 dpi (Figure 3). Data revealed that NK activity decreased in PR8-infected control groups (CON-PR8 and milk-PR8) when compared with the uninfected group (CON), although statistical significance was only found in the milk-PR8 group $(P$ $=0.030)$, but not in CON-PR8 $(P=0.107)$. By contrast, the PY2-PR8 group exhibited significantly higher splenic NK activity than did CON-PR8 and milk-PR8 (both $P$-values were less than 0.001 ) and the uninfected group CON $(P=0.001)$. However, the PY1-PR8 group

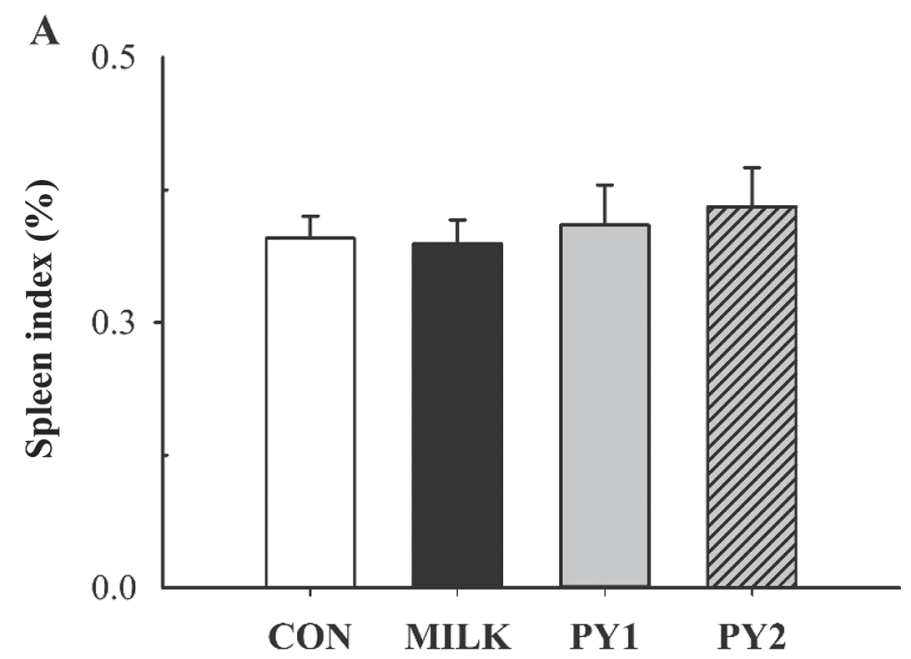

B

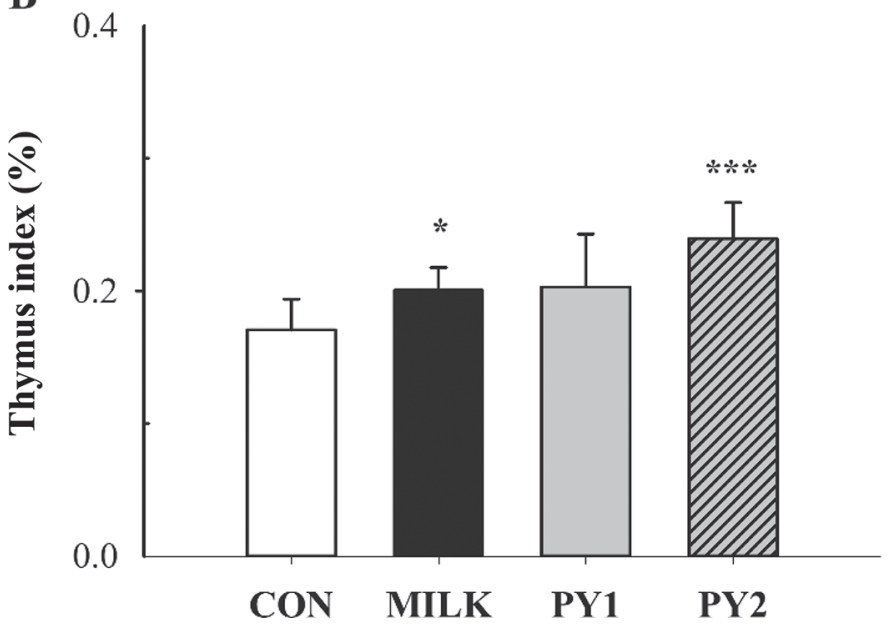

Figure 1. Spleen and thymus indices of mice after 4 wk administration. Spleen, thymus, and body weights were measured at the time of death after 4 wk of daily oral administration. Organ indices were calculated as percentage weight of organs from whole BW of each mouse. (A) Spleen index and (B) thymus index. $\mathrm{CON}=$ PBS only; milk = nonfermented milk only; PY1 $=0.5 \mathrm{mg}$ of $\mathrm{nF} 1$-containing yogurt; $\mathrm{PY} 2$ $=2.5 \mathrm{mg}$ of $\mathrm{nF} 1$-containing yogurt. Data are presented as means \pm $\mathrm{SD}, P$-values were derived from Student's $t$-test compared with CON. ${ }^{*} P<0.05$ and ${ }^{* * *} P<0.001$. Six mice were included per group. 


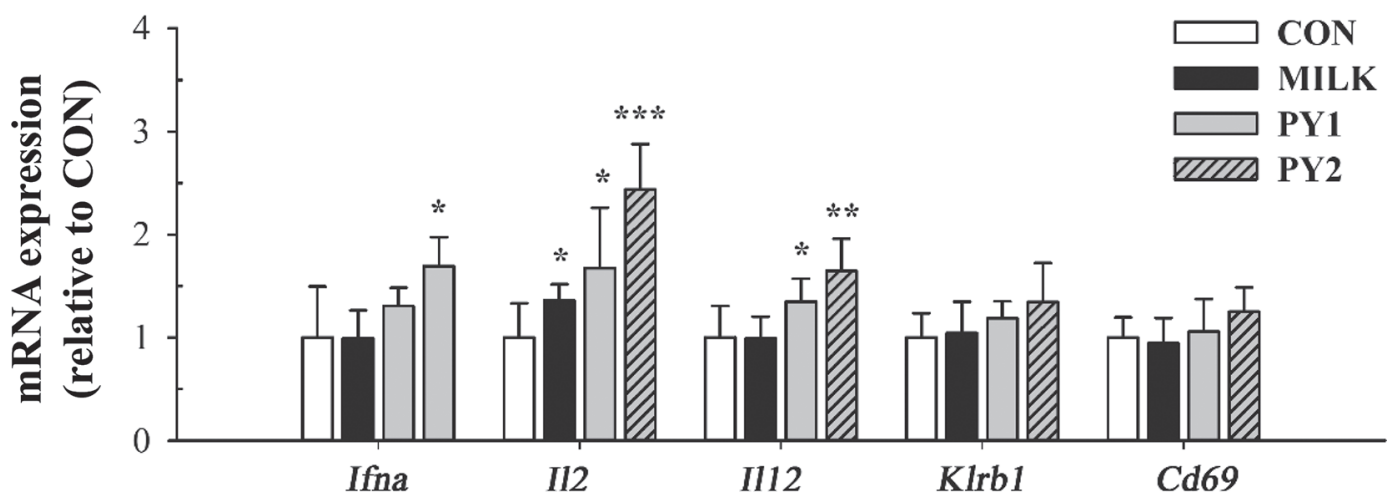

Figure 2. Cytokines and natural killer cell marker gene expressions on the spleen. Transcript levels of Ifna, Il2, Il12, Klrb1, and Cd69 was measured in the spleen after $4 \mathrm{wk}$ of daily oral administration by quantitative reverse transcription PCR using Rn18s as a normalizing control. $\mathrm{CON}=\mathrm{PBS}$ only; milk $=$ nonfermented milk only; PY1 $=0.5 \mathrm{mg}$ of nF1-containing yogurt; PY2 $=2.5 \mathrm{mg}$ of $\mathrm{nF} 1$-containing yogurt. Data are presented as means $\pm \mathrm{SD} ; P$-values were derived from Student's $t$-test compared with each gene of CON. ${ }^{*} P<0.05$, ${ }^{* *} P<0.01$, and $* * * P<$ 0.001. Six mice were included per group.

did not show any change in the NK activity compared with the control infection groups (CON-PR8 and milkPR8). These results suggest that daily consumption of nF1-fortified yogurt with high amounts of nF1 (PY2PR8) may significantly increase NK activity in IAV-

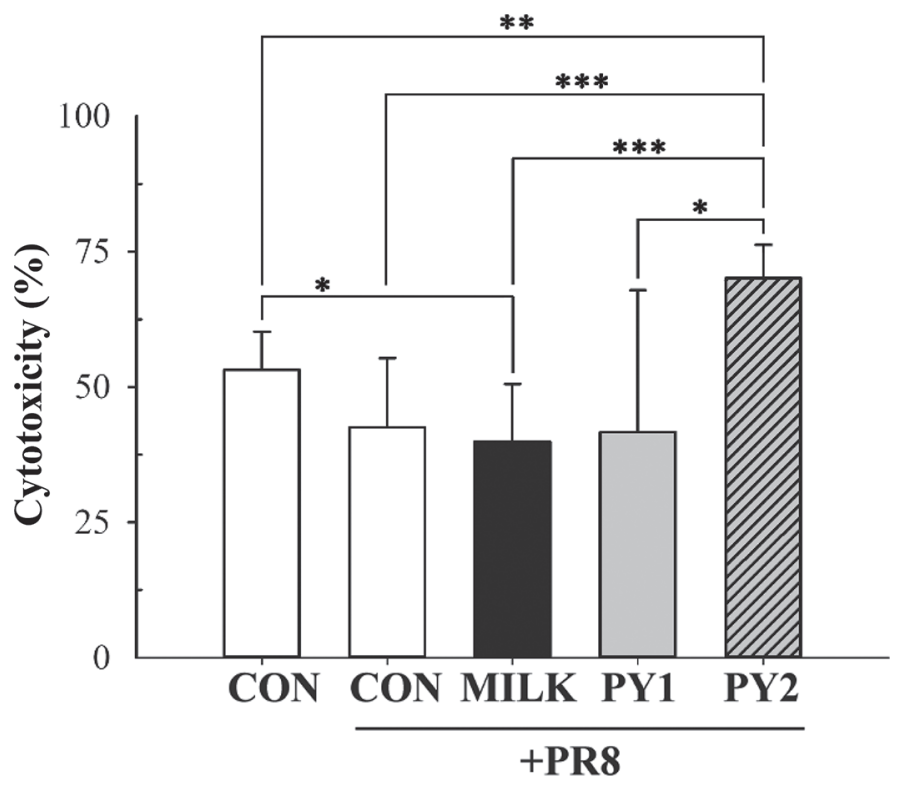

Figure 3. Natural killer (NK) activity of splenocytes after influenza infection. The NK cell cytotoxicity against YAC-1 cells was measured as NK activity using lactate dehydrogenase assay; NK activity was measured in influenza A virus-infected mice spleens at $5 \mathrm{~d}$ postinfection following $21 \mathrm{~d}$ of daily oral administration. The splenocytes from each mouse were incubated with YAC-1 as a target cell for $4 \mathrm{~h}$ (effector:target $=50: 1) . \mathrm{CON}=$ PBS only; milk $=$ nonfermented milk only; PY1 $=0.5 \mathrm{mg}$ of $\mathrm{nF} 1$-containing yogurt; PY2 $=2.5 \mathrm{mg}$ of $\mathrm{nF} 1$ containing yogurt. Data are presented as the means $\pm \mathrm{SD} ; P$-values were derived from Student's $t$-test compared. ${ }^{*} P<0.05$, ${ }^{* *} P<0.01$, and ${ }^{* * *} P<0.001$. Six mice were included per group. infected mice, whereas IAV infection itself lowers NK activity.

\section{Effect of nF1-Fortified Yogurts on Lung Inflammatory Responses Against IAV Infection}

To evaluate the effects of $\mathrm{nF} 1$-fortified yogurt on inflammatory response during IAV infection, transcript levels of proinflammatory cytokines, such as $I l 1 b$ and Il6, were measured in the lung tissues of mice infected as mentioned above. When compared with the uninfected group, all PR8-infected groups showed significantly increased transcript levels of $I l 1 b$ and $I l 6$ (Figure 4). When compared with the control infection groups (CON-PR8 and milk-PR8), the $I l 1 b$ transcript level was further upregulated in PY1-PR8 $(P=0.046$ and $P<0.001)$ and PY2-PR8 groups $(P=0.002$ and $P=$ $0.002)$. In addition, the PY2-PR8 group showed an even further increase in the transcript level when compared with that in PY1-PR8 group $(P=0.023$; Figure 4A). Similar to the $I l 1 b$ transcript, the Il6 transcript level was higher in PY1-PR8 and PY2-PR8 groups than in the control infection groups (CON-PR8 and milk-PR8, $P<0.05)$. However, unlike the $I l 1 b$ transcript levels, no significant difference was observed between the $I l 6$ transcript levels of PY2-PR8 and PY1-PR8 groups $(P$ $=0.401$; Figure 4B). These results indicate that daily yogurt consumption before IAV infection enhanced immune responses such as NK activity and inflammatory cytokine responses.

\section{Protective Effects of nF1-Fortified Yogurt in IAV Infection}

Finally, we tested whether daily consumption of the $\mathrm{nF} 1$-fortified yogurt provides any protective benefits 

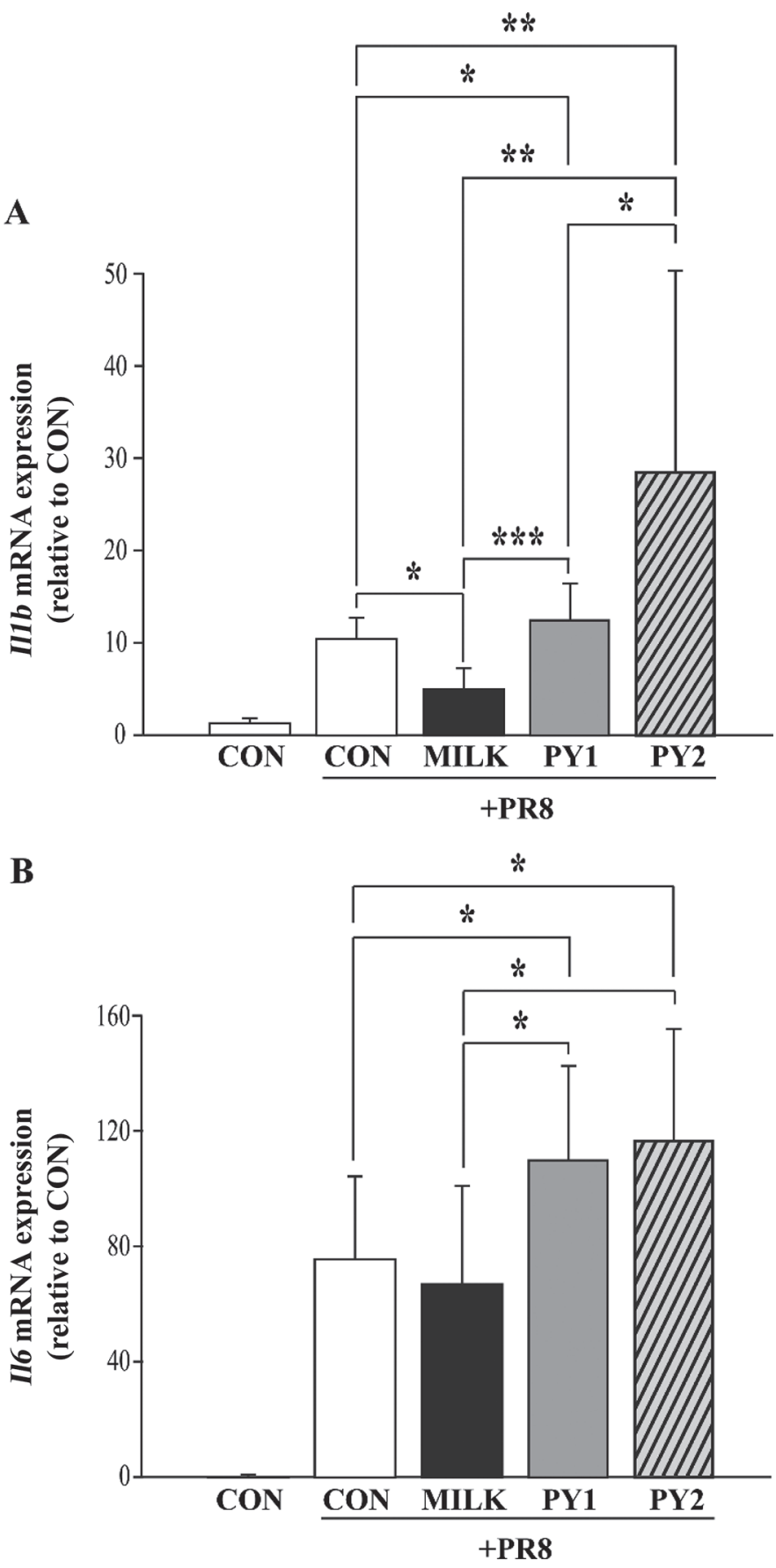

Figure 4. Proinflammatory cytokine expressions in the lung of influenza A virus (IAV)-infected mice. Mice were infected with a mouse-adapted A/Puerto Rico/8/34 H1N1 (PR8) strain of IAV [0.5 $\times$ median lethal doses $\left(\mathrm{LD}_{50}\right)$ per mouse] following $21 \mathrm{~d}$ of daily oral administration with $\mathrm{nF}$-fortified yogurt. Transcript levels of (A) IlIb and (B) Il6 were measured from lung tissue of infected mice at $5 \mathrm{~d}$ postinfection by quantitative reverse transcription PCR using Actb as a normalizing control. $\mathrm{CON}=\mathrm{PBS}$ only; milk $=$ nonfermented milk only; PY1 $=0.5 \mathrm{mg}$ of $\mathrm{nF} 1$-containing yogurt; $\mathrm{PY} 2=2.5 \mathrm{mg}$ of $\mathrm{nF} 1-$ containing yogurt. Data are presented as the means $\pm \mathrm{SD} ; P$-values were derived from Student's $t$-test, compared with PR8-infected CON group. ${ }^{*} P<0.05,{ }^{* *} P<0.01$, and ${ }^{* * *} P<0.001$. Six mice were included per group.

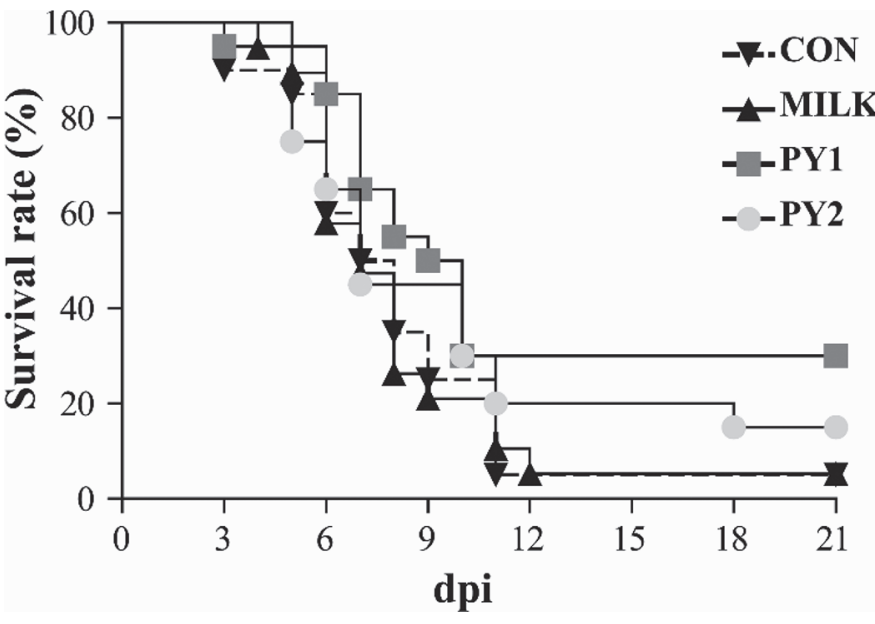

Figure 5. Protective effects of $\mathrm{nF}$ 1-fortified yogurts on mortality following influenza A virus (IAV) infection. Mice were infected with a mouse-adapted A/Puerto Rico/8/34 H1N1 (PR8) strain of IAV [2 $\times$ median lethal doses $\left(\mathrm{LD}_{50}\right)$ per mouse] following $21 \mathrm{~d}$ of daily oral administration of $\mathrm{nF} 1$-fortified yogurt. The mortality of infected mice was monitored for an additional $21 \mathrm{~d}$. Twenty mice were included per group. dpi $=$ days postinfection. $\mathrm{CON}=\mathrm{PBS}$ only; milk $=$ nonfermented milk only; PY1 $=0.5 \mathrm{mg}$ of $\mathrm{nF} 1$-containing yogurt; $\mathrm{PY} 2=2.5$ $\mathrm{mg}$ of $\mathrm{nF} 1$-containing yogurt.

against IAV infection. Mice were infected with a $2 \times$ $\mathrm{LD}_{50}$ dose of PR8 after consuming $\mathrm{nF} 1$ yogurt for $21 \mathrm{~d}$ and monitored for an additional $21 \mathrm{~d}$. The PR8 infection with $2 \times \mathrm{LD}_{50}$ dose resulted in $5 \%$ survival rate in the CON group and $5.3 \%$ survival rate in the milk group (Figure 5); however, PY1 and PY2 groups exhibited significantly increased survival rates of 30 and $15 \%(P$ $<0.001$ for PY1 and $P=0.035$ for PY2), respectively (Bewick et al., 2004; Figure 5). Although the survival rate was not directly correlated with the amount of $\mathrm{nF} 1$ addition, this result indicates that daily yogurt consumption before IAV infection provides protective effects.

\section{DISCUSSION}

Yogurt is an easily accessible product, and the immunological benefits it can confer have received plenty of attention (Meydani and Ha, 2000). Various studies reported that heat-killed probiotics have a similar level of immunomodulatory abilities as live probiotics, despite a lack of viability. In case of Enterococcus faecalis and L. plantarum $06 \mathrm{CC} 2$, administration of heat-treated $\mathrm{LAB}$ on mice before influenza virus infection reduced morbidity and alleviated symptoms (Takeda et al., 2011; Chen et al., 2017b). Therefore, by using heattreated probiotics as an additive, it can be easier to increase immunomodulatory properties of yogurt with prolonged shelf life and easier storage properties. 
Previously, L. plantarum $\mathrm{nF} 1$ showed superior probiotic effects and antioxidant properties over other kimchi-isolated LAB. Lee et al. (2016b) reported that both live and heat-treated L. plantarum $\mathrm{nF} 1$ ameliorates nitric oxide production against inflammation on macrophages due to the cell wall component. Because heat-treated probiotics are mainly composed of cell wall components such as lipoteichoic acid and peptidoglycans without viability, the efficacy of heat-treated probiotics might come from the immune control function from the components (Makino et al., 2006). Nanometric heat-treated L. plantarum $\mathrm{nF} 1$ was reported to improve Il12, Tnfa, and Ifng production in immunosuppressed mice (Lee et al., 2016b; Choi et al., 2018). Administering $\mathrm{nF} 1$-fortified yogurt (the same composition as PY1) improved immune function by increasing NK activity and IL-12 and IFN- $\gamma$ production in immunocompromised elderly subjects (over 60 yr of age; Lee et al., 2017). At a similar age of elderly subjects, fermented yogurt with L. delbrueckii ssp. bulgaricus OLL1073R-1, which has anti-influenza activity, resulted in subjects with lower risk of catching a cold and milder symptoms along with the improved NK activity (Makino et al., 2010; Nagai et al., 2011). In line with these results, our study indicates that $\mathrm{nF}$-fortified yogurt enhances immune function in immunocompetent subjects and immunosuppressed subjects.

Daily administration of PY2 increased the thymus index and transcript levels of NK-activating cytokines in comparison with other groups (Figure 1 and 2). As reported by previous studies, increased thymus and spleen weights can be used as markers of improved immunity, because their weight increases with immune response (Sun et al., 2017; Li et al., 2018). In addition, a relationship between high thymus index and IAV protection was reported by Wang et al. (2016), and the thymus index results in our work indicate that consuming yogurt has a protective effect against IAV infection. Type I IFN, IL-2, and IL-12 are produced by various immune cells upon infection with viruses, and these cytokines can activate NK cells via cytokine specific surface receptors (Marçais et al., 2013). Because NK cells are primed by stimulation with these cytokines from a resting state, expression of surface markers, such as CD25 and CD69, is increased in cytolytic NK cells (Wehner et al., 2011; van Ostaijen-Ten Dam et al., 2016). Activated NK cells have a stronger cytolytic activity because they are better able to produce cytolytic effector molecules, such as perforin and granzymes, which lyse damaged cells. In groups administered with $\mathrm{nF} 1$-fortified yogurt, the increase in gene expression of an NK cell-associated marker, Klrb1, and a lymphoid activation surface marker, $C d 69$, was smaller than the increase in the cytokine gene expressions. These results indicate that the immune-enhancing effect of PY2 could be related to NK activation; however, they also indicate that the effect is not as strong as the effect caused by increasing cytokine expressions or increasing thymus index. Consuming PY2 could affect immunity by increasing the cytokine transcript levels and thymus index; however, milk and PY1 were less effective. Taken together, consuming nF1-fortified yogurt may improve immune systems and NK cell activation by cytokine expression. Likewise, PY2 groups showed the greatest increment among other groups. This suggests that the $\mathrm{nF} 1$ additive in PY1 and PY2 is likely the direct cause of these effects.

To confirm the immune-enhancing effect of $\mathrm{nF} 1-$ fortified yogurt on IAV infection, we examined the NK activity of the IAV-infected mice after administering yogurt for $21 \mathrm{~d}$ before infection. Splenic NK cells directly infected with influenza in vitro lost their cytotoxicity, downregulated cytokine and chemokine expressions, and exhibited decreased NK cell surface receptors. (Guo et al., 2009). Natural killer cells prevent virus replication in infected cells by increasing the IFN- $\gamma$ production to remove infected cells (Vidal et al., 2011). Consistent with the upregulation of NK activating cytokine gene expressions, PY2 administered to mice resulted in higher NK cell cytotoxicity than did seen in the control group mice and milk group mice upon IAV infection (Figure 3). Additionally, type 1 IFN and IL-12 are well known cytokines that activate NK cells and change NK cell responses in IAV infection. Interleukin-12 is a representative NK-activating cytokine, and it has been shown that treatment with IL-12 before IAV infection increases NK cell activity after infection and protects against IAV infection (Ishikawa et al., 2016). It was also reported that IFN- $\alpha$ released from macrophages increases IFN- $\gamma$ production of NK cells and other cytokines in an IAV-infected state (Sirén et al., 2004; Paolini et al., 2015). Thus, cytokines upregulated by PY2 could preactivate NK cells before IAV infection and maintain high NK cell cytotoxicity. However, the PY1 group, which was administered 5 times less $\mathrm{nF} 1$ yogurt, showed little increase in NK cytotoxicity and presented thymus index and cytokine expression similar to that of noninfected mice. The comparison of these 2 different $\mathrm{nF} 1$ compositions in the same yogurt base indicates that the consumption of $\mathrm{nF} 1$ and not yogurt has a greater effect on NK activity. This is consistent with previous reports on NK activity enhancing LAB (LGG, Lactobacillus pentosus S-PT84 and L. delbrueckii OLL1073R-1) in influenza-infected lung or spleen tissues (Harata et al., 2010; Nagai et al., 2011; Makino et al., 2016).

Regarding IAV infection, inflammation may be a double-edged sword. It is required for the development 
of immune response, viral clearance, and recovery from tissue injuries; however, excessive inflammation may lead to detrimental outcomes, such as cytokine storms (Liu et al., 2016; Tavares et al., 2017). The proinflammatory cytokines IL- 6 and IL- $1 \beta$ are critical in controlling IAV infection (Schmitz et al., 2005; Dienz et al., 2012; Lauder et al., 2013). The levels of these cytokines further increase in mice infected with a mouse-adapted PR8 strain of IAV $\left(0.5 \times \mathrm{LD}_{50}\right.$ per mouse $)$ following 21 $\mathrm{d}$ of daily oral administration with $\mathrm{nF} 1$-fortified yogurt when compared with IAV infection alone (Figure 4). These results indicate that daily yogurt administration enhances immune function with NK activity and inflammatory responses to protect the infected host from IAV infection.

The survival rate of mice infected with a lethal dose of IAV further demonstrates the protective effect of $\mathrm{nF} 1$ yogurt consumption. The survival rate was higher in the yogurt-administered groups than in the control or milk-administered groups (Figure 5). It is worth noting that daily yogurt administration has a prophylactic effect, because, in our study, a 21-d regimen of yogurt consumption finished $3 \mathrm{~d}$ before IAV infection. Considering the immune-enhancing effect of daily yogurt administration in normal mice, it is conceivable that this prophylactic effect may have been caused by heightening basal levels of immune responses. Dose-dependent effects of $n F 1$ in the survival rate of mice infected with a lethal dose of IAV were not as pronounced in the PY1 and PY2 groups. It may be that a dose of IAV induces a larger immune response than a sublethal dose and causes excessive secretion of proinflammatory cytokines in the PY2 group. These cytokines, particularly IL$1 \beta$, can augment lung inflammation and pathogenesis during IAV infection (Kim et al., 2015; Indalao et al., 2017), and excessive expression of $I l 1 b$ transcript in the PY2 group may, somehow, negatively affect survival rate during lethal dose infection; the same is also true for NK cells in mice, depending on IAV dose (AbdulCareem et al., 2012; Zhou et al., 2013).

Although the detailed mechanisms of immunological activity related to $\mathrm{nF} 1$ addition against IAV are yet to be elucidated, it is plausible that the uptake of $\mathrm{nF} 1$-fortified yogurt may alter gut microbiota. In previous reports, daily uptake of yogurt or fermented milk resulted in the compositional change of human gut microbiome (Unno et al., 2015; Lisko et al., 2017). Interestingly, changes in microbiome have been reported to modulate IAV infection (Ichinohe et al., 2011; Yaqoob, 2014; Chen et al., 2017a; Yitbarek et al., 2018). As gut microbiota are also suggested to play an important role in the development and function of lymphoid cells, including NK cells (Kamada and Núñez, 2013; Aziz and Bonavida, 2016), nF1-fortified yogurt may induce immunological responses enhancing the NK cell activity and exhibit both protective and prophylactic effects against IAV infection by changing gut microbiome composition. Further studies should investigate the relationship between alterations in gut microbiota and immunological activities following the daily uptake of $n F 1$-fortified yogurt.

In summary, the daily administration of heat-treated L. plantarum $\mathrm{nF}$-fortified yogurt improved immune response in mice, which manifested as upregulation of cytokine expression and NK activity. Administering yogurt before IAV infection also indicated decreased mortality, indicating its preventive effect against IAV infection. Therefore, we suggest that habitual consumption of $\mathrm{nF} 1$-fortified yogurt may provide protection against influenza infection.

\section{ACKNOWLEDGMENTS}

This study was funded by Purmil Co. Ltd. (Seoul, Korea) and the School of Life Sciences \& Biotechnology of Korea University for BK21PLUS. The authors thank the Korea University-CJ Food Safety Center (Seoul, Korea) for providing the equipment and facilities.

\section{REFERENCES}

Abdul-Careem, M. F., M. F. Mian, G. Yue, A. Gillgrass, M. J. Chenoweth, N. G. Barra, M. V. Chew, T. Chan, A. A. Al-Garawi, and M. Jordana. 2012. Critical role of natural killer cells in lung immunopathology during influenza infection in mice. J. Infect. Dis. 206:167-177.

Arimori, Y., R. Nakamura, Y. Hirose, S. Murosaki, Y. Yamamoto, O. Shidara, H. Ichikawa, and Y. Yoshikai. 2012. Daily intake of heatkilled Lactobacillus plantarum L-137 enhances type I interferon production in healthy humans and pigs. Immunopharmacol. Immunotoxicol. 34:937-943.

Aziz, N., and B. Bonavida. 2016. Activation of natural killer cells by probiotics. For. Immunopathol. Dis. Therap. 7:41-55.

Bewick, V., L. Cheek, and J. Ball. 2004. Statistics review 12: Survival analysis. Crit. Care 8:389-394.

Chen, C.-J., G.-H. Wu, R.-L. Kuo, and S.-R. Shih. 2017a. Role of the intestinal microbiota in the immunomodulation of influenza virus infection. Microbes Infect. 19:570-579.

Chen, M. F., K. F. Weng, S. Y. Huang, Y. C. Liu, S. N. Tseng, D. M. Ojcius, and S. R. Shih. 2017b. Pretreatment with a heat-killed probiotic modulates monocyte chemoattractant protein-1 and reduces the pathogenicity of influenza and enterovirus 71 infections. Mucosal Immunol. 10:215-227.

Choi, D. W., S. Jung, J. Kang, Y. Nam, S. Lim, K. Kim, and H. Shin. 2018. Immune-enhancing effect of nanometric Lactobacillus plantarum $\mathrm{nF} 1$ (nLp-nF1) in a mouse model of cyclophosphamideinduced immunosuppression. J. Microbiol. Biotechnol. 28:218-226.

Codex Alimentarius. 2010. Codex Standard for Fermented Milks (CODEX STAN 243-2003). FAO/WHO, Rome, Italy.

Dienz, O., J. G. Rud, S. M. Eaton, P. A. Lanthier, E. Burg, A. Drew, J. Bunn, B. T. Suratt, L. Haynes, and M. Rincon. 2012. Essential role of IL-6 in protection against H1N1 influenza virus by promoting neutrophil survival in the lung. Mucosal Immunol. 5:258-266.

Geiger, T. L., and J. C. Sun. 2016. Development and maturation of natural killer cells. Curr. Opin. Immunol. 39:82-89.

Goto, H., A. Sagitani, N. Ashida, S. Kato, T. Hirota, T. Shinoda, and N. Yamamoto. 2013. Anti-influenza virus effects of both live and 
non-live Lactobacillus acidophilus L-92 accompanied by the activation of innate immunity. Br. J. Nutr. 110:1810-1818.

Guo, H., P. Kumar, T. M. Moran, A. Garcia-Sastre, Y. Zhou, and S. Malarkannan. 2009. The functional impairment of natural killer cells during influenza virus infection. Immunol. Cell Biol. 87:579589 .

Harata, G., F. He, N. Hiruta, M. Kawase, A. Kubota, M. Hiramatsu, and H. Yausi. 2010. Intranasal administration of Lactobacillus rhamnosus GG protects mice from H1N1 influenza virus infection by regulating respiratory immune responses. Lett. Appl. Microbiol. 50:597-602

Ichinohe, T., I. K. Pang, Y. Kumamoto, D. R. Peaper, J. H. Ho, T. S. Murray, and A. Iwasaki. 2011. Microbiota regulates immune defense against respiratory tract influenza A virus infection. Proc. Natl. Acad. Sci. USA 108:5354-5359.

Indalao, I. L., T. Sawabuchi, E. Takahashi, and H. Kido. 2017. IL-13 is a key cytokine that induces trypsin upregulation in the influenza virus-cytokine-trypsin cycle. Arch. Virol. 162:201-211.

Ishikawa, H., S. Ino, H. Sasaki, T. Fukui, C. Kohda, and K. Tanaka. 2016. The protective effects of intranasal administration of IL-12 given before influenza virus infection and the negative effects of IL-12 treatment given after viral infection. J. Med. Virol. 88:14871496.

Kamada, N., and G. Núñez. 2013. Role of the gut microbiota in the development and function of lymphoid cells. J. Immunol. 190:13891395 .

Kawahara, T., T. Takahashi, K. Oishi, H. Tanaka, M. Masuda, S. Takahashi, M. Takano, T. Kawakami, K. Fukushima, H. Kanazawa, and T. Suzuki. 2015. Consecutive oral administration of Bifidobacterium longum MM-2 improves the defense system against influenza virus infection by enhancing natural killer cell activity in a murine model. Microbiol. Immunol. 59:1-12.

Kikuchi, Y., A. Kunitoh-Asari, K. Hayakawa, S. Imai, K. Kasuya, K. Abe, Y. Adachi, S.-i. Fukudome, Y. Takahashi, and S. Hachimura. 2014. Oral administration of Lactobacillus plantarum strain AYA enhances IgA secretion and provides survival protection against influenza virus infection in mice. PLoS One 9:e86416.

Kim, K. S., H. Jung, I. K. Shin, B. R. Choi, and D. H. Kim. 2015. Induction of interleukin-1 beta (IL-1 $\beta$ ) is a critical component of lung inflammation during influenza A (H1N1) virus infection. J. Med. Virol. 87:1104-1112.

Kreijtz, J. H., R. A. Fouchier, and G. F. Rimmelzwaan. 2011. Immune responses to influenza virus infection. Virus Res. 162:19-30.

Lanier, L. L. 2008. Up on the tightrope: Natural killer cell activation and inhibition. Nat. Immunol. 9:495-502.

Lauder, S. N., E. Jones, K. Smart, A. Bloom, A. S. Williams, J. P. Hindley, B. Ondondo, P. R. Taylor, M. Clement, and C. Fielding. 2013. Interleukin-6 limits influenza-induced inflammation and protects against fatal lung pathology. Eur. J. Immunol. 43:2613-2625.

Lee, A., Y. Lee, H. Yoo, M. Kim, Y. Chang, D. Lee, and J. Lee. 2017. Consumption of dairy yogurt containing Lactobacillus paracasei ssp. paracasei, Bifidobacterium animalis ssp. lactis and heat-treated Lactobacillus plantarum improves immune function including natural killer cell activity. Nutrients 9:558.

Lee, H. A., H. Kim, K.-W. Lee, and K.-Y. Park. 2016a. Dead Lactobacillus plantarum stimulates and skews immune responses toward T helper 1 and 17 polarizations in RAW 264.7 cells and mouse splenocytes. J. Microbiol. Biotechnol. 26:469-476.

Lee, X. M., H. A. Lee, M. Kweon, E. S. Park, and K. Y. Park. 2016b. Probiotic effects of Lactobacillus plantarum strains isolated from kimchi. J. Korean Soc. Food Sci. Nutr. 45:1717-1724.

Li, Q., F. Zhang, G. Chen, Y. Chen, W. Zhang, G. Mao, T. Zhao, M. Zhang, L. Yang, and X. Wu. 2018. Purification, characterization and immunomodulatory activity of a novel polysaccharide from Grifola frondosa. Int. J. Biol. Macromol. 111:1293-1303.

Lisko, D. J., G. P. Johnston, and C. G. Johnston. 2017. Effects of dietary yogurt on the healthy human gastrointestinal (GI) microbiome. Microorganisms 5:6.

Liu, Q., Y. H. Zhou, and Z. Q. Yang. 2016. The cytokine storm of severe influenza and development of immunomodulatory therapy. Cell. Mol. Immunol. 13:3-10.
Livak, K. J., and T. D. Schmittgen. 2001. Analysis of relative gene expression data using real-time quantitative PCR and the $2^{-\triangle \Delta C T}$ method. Methods 25:402-408.

Maeda, N., R. Nakamura, Y. Hirose, S. Murosaki, Y. Yamamoto, T. Kase, and Y. Yoshikai. 2009. Oral administration of heat-killed Lactobacillus plantarum L-137 enhances protection against influenza virus infection by stimulation of type I interferon production in mice. Int. Immunopharmacol. 9:1122-1125.

Makino, S., S. Ikegami, H. Kano, T. Sashihara, H. Sugano, and H. Horiuchi. 2006. Immunomodulatory effects of polysaccharides produced by Lactobacillus delbrueckii ssp. bulgaricus OLL1073R-1. J. Dairy Sci. 89:2873-2881

Makino, S., S. Ikegami, A. Kume, H. Horiuchi, H. Sasaki, and N. Orii. 2010. Reducing the risk of infection in the elderly by dietary intake of yoghurt fermented with Lactobacillus delbrueckii ssp. bulgaricus OLL1073R-1. Br. J. Nutr. 104:998-1006.

Makino, S., A. Sato, A. Goto, M. Nakamura, M. Ogawa, Y. Chiba, J. Hemmi, H. Kano, K. Takeda, K. Okumura, and Y. Asami. 2016. Enhanced natural killer cell activation by exopolysaccharides derived from yogurt fermented with Lactobacillus delbrueckii ssp. bulgaricus OLL1073R-1. J. Dairy Sci. 99:915-923.

Marçais, A., S. b. Viel, M. Grau, T. Henry, J. Marvel, and T. Walzer. 2013. Regulation of mouse NK cell development and function by cytokines. Front. Immunol. 4:450.

Meng, H., Y. Lee, Z. Ba, J. Peng, J. Lin, A. S. Boyer, J. A. Fleming, E. J. Furumoto, R. F. Roberts, P. M. Kris-Etherton, and C. J Rogers. 2016. Consumption of Bifidobacterium animalis ssp. lactis BB-12 impacts upper respiratory tract infection and the function of NK and T cells in healthy adults. Mol. Nutr. Food Res. 60:1161-1171

Meydani, S. N., and W. K. Ha. 2000. Immunologic effects of yogurt. Am. J. Clin. Nutr. 71:861-872.

Nagai, T., S. Makino, S. Ikegami, H. Itoh, and H. Yamada. 2011. Effects of oral administration of yogurt fermented with Lactobacillus delbrueckii ssp. bulgaricus OLL1073R-1 and its exopolysaccharides against influenza virus infection in mice. Int. Immunopharmacol. 11:2246-2250

Nishimura, M., T. Ohkawara, K. Tetsuka, Y. Kawasaki, R. Nakagawa, H. Satoh, Y. Sato, and J. Nishihira. 2015. Effects of yogurt containing Lactobacillus plantarum HOKKAIDO on immune function and stress markers. J. Tradit. Complement. Med. 6:275-280.

Orr, M. T., and L. L. Lanier. 2010. Natural killer cell education and tolerance. Cell 142:847-856.

Palese, P. 2004. Influenza: Old and new threats. Nat. Med. 10(Suppl.):S82-S87.

Paolini, R., G. Bernardini, R. Molfetta, and A. Santoni. 2015. NK cells and interferons. Cytokine Growth Factor Rev. 26:113-120.

Schmitz, N., M. Kurrer, M. F. Bachmann, and M. Kopf. 2005. Interleukin-1 is responsible for acute lung immunopathology but increases survival of respiratory influenza virus infection. J. Virol. 79:6441-6448.

Schultz-Cherry, S. 2015. Role of NK cells in influenza infection. Curr. Top. Microbiol. Immunol. 386:109-120.

Shida, K., T. Sato, R. Iizuka, R. Hoshi, O. Watanabe, T. Igarashi, K. Miyazaki, M. Nanno, and F. Ishikawa. 2017. Daily intake of fermented milk with Lactobacillus casei strain Shirota reduces the incidence and duration of upper respiratory tract infections in healthy middle-aged office workers. Eur. J. Nutr. 56:45-53.

Sirén, J., T. Sareneva, J. Pirhonen, M. Strengell, V. Veckman, I. Julkunen, and S. Matikainen. 2004. Cytokine and contact-dependent activation of natural killer cells by influenza A or Sendai virus-infected macrophages. J. Gen. Virol. 85:2357-2364.

Sun, H.-Q., Z.-Y. Zhu, X.-Y. Yang, M. Meng, L.-C. Dai, and Y.-M. Zhang. 2017. Preliminary characterization and immunostimulatory activity of a novel functional polysaccharide from Astragalus residue fermented by Paecilomyces sinensis. RSC Advances $7: 23875-23881$.

Sun, J. C., and L. L. Lanier. 2011. Natural killer cell response against viruses. Pages 197-207 in The Immune Response to Infection. American Society of Microbiology Press, Washington, DC. 
Szretter, K. J., A. L. Balish, and J. M. Katz. 2013. Influenza: Propagation, quantification, and storage. Curr Protoc. Microbiol. 29:15G.11.11-15G.11.24

Takeda, S., M. Takeshita, Y. Kikuchi, B. Dashnyam, S. Kawahara, H. Yoshida, W. Watanabe, and M. Kurokawa. 2011. Efficacy of oral administration of heat-killed probiotics from Mongolian dairy products against influenza infection in mice: alleviation of influenza infection by its immunomodulatory activity through intestinal immunity. Int. Immunopharmacol. 11:1976-1983.

Taubenberger, J. K., and D. M. Morens. 2008. The pathology of influenza virus infections. Annu. Rev. Pathol. 3:499-522.

Taubenberger, J. K., and D. M. Morens. 2010. Influenza: The once and future pandemic. Public Health Rep. 125(Suppl. 3):16-26.

Tavares, L. P., M. M. Teixeira, and C. C. Garcia. 2017. The inflammatory response triggered by Influenza virus: A two edged sword. Inflamm. Res. 66:283-302.

Unno, T., J.-H. Choi, H.-G. Hur, M. J. Sadowsky, Y.-T. Ahn, C.-S. Huh, G.-B. Kim, and C.-J. Cha. 2015. Changes in human gut microbiota influenced by probiotic fermented milk ingestion. J. Dairy Sci. 98:3568-3576.

van Ostaijen-Ten Dam, M. M., H.-J. Prins, G. H. Boerman, C. Vervat, D. Pende, H. Putter, A. Lankester, M. J. Van Tol, J. J. Zwaginga, and M. W. Schilham. 2016. Preparation of cytokine-activated NK cells for use in adoptive cell therapy in cancer patients: protocol optimization and therapeutic potential. J. Immunother. 39:90-100.

Vidal, S. M., S. I. Khakoo, and C. A. Biron. 2011. Natural killer cell responses during viral infections: flexibility and conditioning of innate immunity by experience. Curr. Opin. Virol. 1:497-512.
Vivier, E., E. Tomasello, M. Baratin, T. Walzer, and S. Ugolini. 2008. Functions of natural killer cells. Nat. Immunol. 9:503-510.

Wang, S., C. Chen, Z. Yang, X. Chi, J. Zhang, and J.-L. Chen. 2016. Targeted disruption of influenza A virus hemagglutinin in genetically modified mice reduces viral replication and improves disease outcome. Sci. Rep. 6:23746.

Wehner, R., K. Dietze, M. Bachmann, and M. Schmitz. 2011. The bidirectional crosstalk between human dendritic cells and natural killer cells. J. Innate Immun. 3:258-263.

Yaqoob, P. 2014. Ageing, immunity and influenza: A role for probiotics? Proc. Nutr. Soc. 73:309-317.

Yitbarek, A., T. Alkie, K. Taha-Abdelaziz, J. Astill, J. RodriguezLecompte, J. Parkinson, É. Nagy, and S. Sharif. 2018. Gut microbiota modulates type I interferon and antibody-mediated immune responses in chickens infected with influenza virus subtype H9N2. Benef. Microbes 9:417-427.

Yu, Z. P., D. D. Xu, L. F. Lu, X. D. Zheng, and W. Chen. 2016. Immunomodulatory effect of a formula developed from American ginseng and Chinese jujube extracts in mice. J. Zhejiang Univ. Sci. B 17:147-157.

Zhou, G., S. W. W. Juang, and K. P. Kane. 2013. NK cells exacerbate the pathology of influenza virus infection in mice. Eur. J. Immunol. 43:929-938. 